\title{
A cross-sectional study of fertile period awareness, knowledge, attitudes and practice in infertile couples seeking fertility assistance
}

\author{
Shilpa Pankaj Kshrisagar, Arti Sidharth Shirsath*
}

Department of Obstetrics and Gynecology, Smt Kashibai Navale Medical College and General Hospital, Pune, Maharashtra, India

Received: 05 July 2018

Accepted: 02 August 2018

\section{*Correspondence:}

Dr. Arti Sidharth Shirsath,

E-mail: arti.sirsath@gmail.com

Copyright: () the author(s), publisher and licensee Medip Academy. This is an open-access article distributed under the terms of the Creative Commons Attribution Non-Commercial License, which permits unrestricted non-commercial use, distribution, and reproduction in any medium, provided the original work is properly cited.

\begin{abstract}
Background: Infertility is one of the most distressful condition for a couple. Medical interventions may exacerbate anxiety, depression, stress, loss of self-esteem, guilt and grief in these couples. But many studies indicate that most cases of infertility can be attributed to a physiological cause in the man or woman. Previous research has suggested that poor fertility period awareness may be a contributing cause of infertility among couples seeking assistance at infertility clinics. The actual practices and attitudes towards fertility-awareness in this particular group of patients are unknown and need to be explored. The aim of the present study was to report the study of fertile period awareness and their knowledge, attitude and practice in the infertile couples seeking fertility assistance

Methods: This is a cross-sectional questionnaire-based study. The study was conducted over a period of 6 months from June to December 2017 in the couples attending the infertility clinic at Smt Kashibai Navale Medical College and General Hospital, Pune.

Results: Total 246 of 280 distributed questionnaires were completed (response rate $=87.8 \%$ ). Out of these $60 \%$ $(n=147)$ believed they had timed intercourse within the fertile window of the menstrual cycle in their attempts at conception, but surprisingly only $36 \%(n=52)$ could accurately identify this window. In this study 23\% ( $=56$ ) participants had already taken prior treatment but still $50 \%$ were ignorant about fertile window. It was shocking that among 246 only $15 \%(n=38)$ couples were actually practising fertile period due to some reasons and most of them did not know or rely upon the concept of fertile period. Almost $94 \%$ of them believed that they should receive fertilityawareness education when they first report trouble in conceiving to their doctor.

Conclusions: Most couples seeking assistance at infertility clinics were unaware of the fertile window of the menstrual cycle and only few could accurately identify this window, suggesting that poor fertility awareness may be a contributing cause of infertility.
\end{abstract}

Keywords: Fertile period, Fertile window, Fertility-awareness, Infertility

\section{INTRODUCTION}

Childbirth is considered a major component of human life; most men and women take parenthood for granted and look forward to it. Infertility is a global phenomenon which affects both men and women with almost equal frequency. ${ }^{1}$ A couple is generally considered clinically infertile when pregnancy has not occurred after at least twelve months of regular unprotected sexual activity. ${ }^{2}$ Prevalence of primary infertility in India is between 3.9 and $16.8 \% .^{3}$ Infertility is a source of distress for couples. Societal norms may correlate infertility with failure on a personal, interpersonal, emotional or social level. Women bear the brunt of these societal perceptions in most of the 
cases. Psychologically, the infertile woman exhibits significantly higher psychopathology in the form of tension, anxiety. In India it is reported that $70 \%$ of women experiencing infertility are blamed. ${ }^{4-5}$ Exploration of the societal perceptions of infertility can assist clinical work, providing better help to infertile couples.

Knowledge about infertility is inadequate in many parts of the world. Many women have little awareness of the fertile window, period of the month in which they are most fertile. ${ }^{6,7}$ These patients are then subjected to unnecessary investigations and subsequent use of assisted reproductive techniques. ART-conceived pregnancies when compared with naturally conceived pregnancies are associated with higher perinatal morbidity and mortality for both mothers and babies. ${ }^{8-10}$

The purpose of this study is to achieve a better understanding of the infertile couples' awareness of fertile period. Our study focussed the need to understand the physiology behind fertility first, before exploring the pathology behind it.

\section{METHODS}

A cross-sectional survey was conducted on infertile couples from the outpatient department at Smt Kashibai Navale Medical College and Hospital over a period of 6 months. All infertile couples at their first visit were given a questionnaire which included close ended 15 questions. Questionnaire was divided in subsections like demographic data of patient, patient's knowledge about awareness of fertile period in menstrual cycle and their practices towards it along with social perceptions of infertility. Source of information for fertile period was also noted. Questionnaire was in local language that is Marathi as well as in English.

\section{Inclusion criteria}

- Infertile couples attending the infertility clinic at SKNMC and GH for the first time

- Infertile couples in the age group of 18 to 45 years.

- Infertile couples who were ready to participate in the study.

\section{Exclusion criteria}

- Patients who were not willing to participate in the study

- Couples who were prior registered under infertility clinic at SKNMCH.

The research protocol was reviewed and approved by the ethics review Committee at the Smt. Kashibai Navale Medical college. All subjects had the right to withdraw from the study anytime they wished without giving any explanation. The questionnaire was anonymous and ensured confidentiality of the study participants. Written informed consent was taken from each participant prior to the interview.

\section{RESULTS}

\section{Socio-demographic characteristics of the sample}

Total of 280 couples were approached to participate in this survey. 246 couples agreed to participate; therefore, the response rate in the study was $87.8 \%$. Respondent's ages ranged from 18 to 44 years old with a mean age of 26 years. Participants were classified according to their educational status into level I (Illiterate), level II (primary education) and level III (secondary education), level IV (graduates) and level V (Post graduates). Maximum i.e. $37 \%$ of the sample belonged to level III (Table 1). $68 \%$ of these couples were from Hindu community.

Table 1: Socio demographic profile of couples interviewed.

\begin{tabular}{|lll|}
\hline Age & N & $\%$ \\
\hline $18-25$ & 132 & $54 \%$ \\
\hline $26-35$ & 68 & $27 \%$ \\
\hline $36-45$ & 46 & $19 \%$ \\
\hline Education Level & & \\
\hline I & 10 & $4 \%$ \\
\hline II & 68 & $28 \%$ \\
\hline III & 90 & $37 \%$ \\
\hline IV & 60 & $24 \%$ \\
\hline V & 18 & $7 \%$ \\
\hline Religion & & \\
\hline Hindu & 167 & $68 \%$ \\
\hline Muslim & 73 & $30 \%$ \\
\hline Others & 6 & $2 \mathrm{P} \%$ \\
\hline
\end{tabular}

\section{Knowledge and attitude towards fertile period}

Only $38 \%$ of participants correctly identified that both male and female are equally responsible for infertility. $60 \%(n=147)$ of the participants were aware that there is a fertile period during a female's menstrual cycle. However, when they were asked to identify that period from the choices given (immediate post-menses, mid cycle or pre-menses), only $36 \%(n=52)$ of them could correctly identify it to be mid-cycle (Table 2). Out of 52 couples who identified fertile period correctly, major source of correct information was medical personnel followed by internet and majority of them belonged to education level 4 and 5. It is surprising to note that major source of incorrect information was from relatives.

Participants were further asked to identify the major causes of infertility from the list provided. More than $40 \%$ of the participants correctly identified pathology like irregularity of menses, blocked tubes and genital tract infections as a cause of infertility. Many interesting responses were observed: $28 \%$ of them did not know the cause of infertility, $20 \%$ of participants thought that 
previous use of oral contraceptive pill (OCP) and intrauterine contraception device (IUCD), leads to infertility. It was very distressing to know that still in this era $10 \%$ of the couples believed on myths like sin or black magic as the cause of infertility (Table 3 ).

Table 2: Knowledge of respondent regarding concept and timing of fertile period.

\begin{tabular}{|c|c|c|}
\hline Concept of fertile period & $\mathbf{N}$ & $\%$ \\
\hline Yes & 147 & $60 \%$ \\
\hline No & 99 & $40 \%$ \\
\hline \multicolumn{3}{|l|}{ Timing of fertile period } \\
\hline Immediate post menstrual & 58 & $40 \%$ \\
\hline Mid- cycle & 52 & $36 \%$ \\
\hline Pre- menstrual & 36 & $24 \%$ \\
\hline
\end{tabular}

Table 3: Knowledge of respondent regarding causes of infertility.

\begin{tabular}{|c|c|c|}
\hline & $\mathbf{N}$ & $\%$ \\
\hline Pathology & 103 & $42 \%$ \\
\hline Previous contraceptive use & 49 & $20 \%$ \\
\hline Myths & 25 & $10 \%$ \\
\hline Not known & 69 & $28 \%$ \\
\hline
\end{tabular}

\section{Practise of fertility awareness}

Out of 246 couples included in the study only 38(15\%) were practising fertile period. Rest $85 \%$ were either unaware or did not rely, hence were not practising fertile window period in an attempt to conceive. Out of these 56 $(23 \%)$ has already taken prior treatment (Table 4). It was surprising that among 56 only $28(50 \%)$ couples were practising fertile period and rest $50 \%$ did not know the concept of fertile period inspite of taking prior treatment under medical personnel.

Table 4: Practices of fertility period.

\begin{tabular}{|lll|}
\hline Practising fertility period & N & $\%$ \\
\hline Yes & 38 & $15 \%$ \\
\hline No & 208 & $85 \%$ \\
\hline Previous treatment taken & & \\
\hline Yes & 56 & $23 \%$ \\
\hline No & 190 & $77 \%$ \\
\hline
\end{tabular}

\section{DISCUSSION}

The results of this study indicate that knowledge about fertile period is limited in the study population. Women with poor fertility awareness and those who over estimate their little knowledge, both can have implications on the fertility.

In this study authors found that $64 \%$ couples cannot accurately identify the fertile window of the menstrual cycle. This was comparable with the study by Blake et al. Attempted timed intercourse in our study is $15 \%$, which is again comparable with results of the study by Blake et al. $^{4}$

One of the surprising results found in this study was that only $60 \%$ participants knew about the concept of fertile period and among all only $52(36 \%)$ of the participants correctly identified mid-cycle as the most fertile period during the female's menstrual cycle. These results were lower than the results in the study of Sumera Ali et al. ${ }^{7}$ This may be due to difference in the educational level of the demographic population. The lack of accurate information in these patients may lead to improper timing of sexual intercourse, thus possibly delaying the pregnancy.

All couples having trouble conceiving who wish to time intercourse within the fertile window should be supported to attain high fertility-awareness and only be referred on to ART clinics after applying this approach in a minimum of six menstrual cycles, as this is necessary to optimize the chance of natural conception (Wilcox et al, Colombo et al, Stanford et al). ${ }^{11-13}$ Although intercourse 2-3 times per week (as the current guideline recommends) will probably result in one to two acts of intercourse occurring within the fertile window, this regimen may be difficult for some couples to maintain and unsatisfactory for others for a number of reasons (Scarpa et al). ${ }^{14}$

In this study only $50 \%$ of patients who had taken prior treatment for infertility were actually practising fertile period. Rest of the patients were lacking in knowledge and proper counselling about timed intercourse inspite of having prior consultation. This indicates there is lack of counselling and proper advice given by the health care providers.

\section{CONCLUSION}

Authors confirm that most women seeking fertility assistance cannot accurately identify the fertile window of the menstrual cycle. We should emphasise on understanding the physiology before exploring pathology behind infertility. Pivotal role of counselling may reduce economical and emotional burden of couples in ART clinics. At the same time, it will limit the use of resources for actually needy couples.

\section{Funding: No funding sources \\ Conflict of interest: None declared}

Ethical approval: The study was approved by the Institutional Ethics Committee

\section{REFERENCES}

1. Callahan LT, Caughey AB. Blueprints Obstetrics and Gynecology. 5. Lippincott Williams and Wilkins. Infertility and assisted reproductive technologies. 2008. 275-289.

2. Sohrabvand F, Jafarabadi M. Knowledge and attitudes of infertile couples about assisted 
reproductive technology. Iranian J Reprod Med. 2005;3(2):90.

3. WHO. Infecundity, Infertility, and childlessness in developing countries. DHS comparative reports no 9. Calverton, Maryland, USA: ORC Macro and WHO; 2004.

4. Blake D, Smith D, Bargiacchi A, France M, Gudex G. Fertility awareness in women attending a fertility clinic. Aus NZ J Obstetr Gynaecol. 1997 Aug;37(3):350-2.

5. Adashi EY, Cohen J, Hamberger L, Jones HW Jr, de Kretser DM, Lunenfeld B, et al. Public perception on infertility and its treatment: an international survey. The bertarelli foundation scientific board. Hum Reprod. 2000;15(2):330-4.

6. Frank-Herrmann P, Gnoth C, Baur S, Strowitzki T, Freundl G. Determination of the fertile window: reproductive competence of women-European cycle databases. Gynecol Endocrinol. 2005;20(6):305-12.

7. Ali S, Sophie R, Imam AM, Khan FI, Ali SF, Shaikh A, Farid-ul-Hasnain S. Knowledge, perceptions and myths regarding infertility among selected adult population in Pakistan: a cross-sectional study. BMC Public Health. 2011 Dec;11(1):760.

8. Chambers GM, Chapman MG, Grayson N, Shanahan M, Sullivan EA. Babies born after ART treatment cost more than non-ART babies: a cost analysis of inpatient birth-admission costs of singleton and multiple gestation pregnancies. Hum Reprod. 2007 Sep 28;22(12):3108-15.

9. Hansen M, Bower C, Milne E, de Klerk N, Kurinczuk J. Assisted reproductive technologies and the risk of birth defects: a systematic review. Hum Reprod. 2005 Feb 1;20(2):328-38.

10. Fisher JR, Hammarberg K, Baker HG, McBain JC. Assessing the health and development of ARTconceived young adults: A study of feasibility, parent recall, and acceptability. Reprod Health. 2008 Dec;5(1):7.

11. Wilcox AJ, Weinberg CR, Baird DD. Timing of sexual intercourse in relation to ovulation- effects on the probability of conception, survival of the pregnancy, and sex of the baby. N Eng J Med. 1995 Dec 7;333(23):1517-21.

12. Stanford JB, White Jr GL, Hatasaka H. Timing intercourse to achieve pregnancy: current evidence. Obstetr Gynecol. 2002 Dec 1;100(6):1333-41.

13. Colombo B, Masarotto G, Menstrual Cycle Fecundability Study Group. Daily fecundability: first results from a new data base. Demographic Res. 2000 Jul 1;3.

14. Scarpa B, Dunson DB, Giacchi E. Bayesian selection of optimal rules for timing intercourse to conceive by using calendar and mucus. Fertil Steril. 2007 Oct $1 ; 88(4): 915-24$.

Cite this article as: Kshrisagar SP, Shirsath AS. A cross-sectional study of fertile period awareness, knowledge, attitudes and practice in infertile couples seeking fertility assistance. Int J Reprod Contracept Obstet Gynecol 2018;7:3744-7. 